\title{
PRINCIPAIS SISTEMAS ATMOSFÉRICOS ATUANTES SOBRE A REGIÃO NORDESTE DO BRASIL E A INFLUÊNCIA DOS OCEANOS PACÍFICO E ATLÂNTICO NO CLIMA DA REGIÃO ${ }^{1}$
}

\author{
Antonio Geraldo Ferreira², Namir Giovanni da Silva Mello ${ }^{3}$
}

\begin{abstract}
RESUMO
Este trabalho descreve os principais sistemas atmosféricos de pequena, meso e grande escala que influenciam o tempo e o clima da Região Nordeste do Brasil, tais como: zona de convergência inter-tropical, frentes de nuvens, vórtice troposférico dos altos níveis, brisa marítima e outros. Também são descritas as influências dos oceanos Pacífico e Atlântico sobre o clima dessa região.
\end{abstract}

Palavras chave: sistemas atmosféricos, Nordeste do Brasil.

\section{MAIN ATMOSPHERIC SYSTEMS ACTING OVER THE NORTHEASTERN REGION OF BRAZIL AND THE INFLUENCE OF PACIFIC ANS ATLANTIC OCEANS ON THE REGION CLIMATE}

\begin{abstract}
This work describes the main atmospheric systems of small, meso and large scale that have influences on the weather and the climate of the Northeastern Brazilian Region, such as: Intertropical Convergence Zone, Cloud Fronts, Upper Level Tropospheric Vortex, Sea Breeze, and others. The influence of the Pacific and Atlantic oceans on the climate of this region is described too.
\end{abstract}

Keywords: atmospheric systems, Brazilian Northeast.

1 Palestra apresentada em mesa redonda do VI Simpósio Brasileiro de Climatologia, 13 a 16 de outubro de 2004, Aracaju, SE.

2 Fundação Cearense de Meteorologia e Recursos Hídricos; Mestrando do Instituto de Ciências do Mar (LABOMAR) - Universidade Federal do Ceará, Av. da Abolição, 1246 - CEP 60120-332 Fortaleza-CE, geraldo@funceme.br

3 Fundação Cearense de Meteorologia e Recursos Hídricos; Mestrando da Universidade Federal do Ceará - Depto. de Engenharia Hidráulica e Ambiental Campus do PICI - CEP 60451-970 - Caixa Postal 6018 - Fortaleza-CE, namir@funceme.br 


\section{Introdução}

O clima de qualquer região é determinado em grande parte pela circulação geral da atmosfera. Essa, resulta em última instância, do aquecimento diferencial do globo pela radiação solar, da distribuição assimétrica de oceanos e continentes e também das características topográficas sobre os continentes. Padrões de circulação gerados na atmosfera redistribuem calor, umidade e momentum (quantidade de movimento) por todo o globo. No entanto, essa redistribuição não é homogênea, agindo algumas vezes no sentido de diminuir as variações regionais dos elementos climáticos, tais como, temperatura e precipitação, as quais, têm enorme influência nas atividades humanas (Boletim de Monitoramento e Análise Climática-Climanálise-Número Especial, 1986).

Do ponto de vista climático a região Nordeste do Brasil é considerada semi-árida por apresentar substanciais variações temporal e espacial da precipitação pluviométrica, e elevadas temperaturas ao longo do ano (Azevedo, P. V. et al., 1998). Apesar das elevadas temperaturas registradas durante todo o ano, as amplitudes térmicas máximas são em torno de $6^{\circ} \mathrm{C}$.

Em geral, segundo Uvo e Berndtsson (1996), quatro mecanismos governam o regime de chuva da região: 1) Eventos El Niño-Oscilação Sul (ENOS); 2) Temperatura da superfície do mar (TSM) na bacia do oceano Atlântico, Ventos Alísios, Pressão ao Nível do Mar (PNM); 3) Zona de Convergência Intertropical (ZCIT) sobre o oceano Atlântico, 4) Frentes Frias, e 5) Vórtices Ciclônicos de Altos Níveis (VCAN). Além desses mecanismos podemos destacar também a atuação das linhas de Instabilidade (LI), dos Complexos Convectivos de Mesoescala (CCM) (Ramos et Ali, 1994), e do efeito das brisas marítima e terrestre na precipitação. Esses mecanismos são brevemente descritos a seguir.

\section{A circulação atmosférica sobre a região tropical}

A circulação atmosférica sobre a região tropical é fortemente modulada e modificada pelos padrões termodinâmicos sobre as bacias dos oceanos Pacífico e Atlântico Tropicais. Em anos nos quais se verificam anomalias positivas ou negativas da Temperatura da Superfície do Mar (TSM) nas bacias desses oceanos, a célula de Hadley, que atua no sentido meridional (ramo ascendente sobre os trópicos e ramos descendentes nas latitudes subtropicais), e a célula de Walker, que atua no sentido zonal (ramo ascendente no Pacífico oeste e ramo descendente no Pacífico leste) são perturbadas, causando fortes anomalias na circulação atmosférica sobre os trópicos, visto que essas células são deslocadas de suas posições climatológicas (Figuras 1, 2 e 3). Conseqüentemente as intensidade e duração do período chuvoso dessa região também são afetadas. 




Figura 1. Esquematização da Célula de Walker sobre a Bacia do Pacífico Tropical. Sob condições normais observa-se o ramo ascendente da Célula de Walker (favorável à formação de nuvens convectivas profundas) sobre o Pacífico oeste e Austrália onde tem-se águas quentes e pressões baixas. Por outro lado, sobre a região do Pacífico leste, próximo do Peru e Equador, onde verifica-se a presença de águas frias (devido a ressurgência - afloramento na superfície das águas oceânicas advindas do fundo do Oceano Pacífico) e pressões altas, manifesta-se o ramo subsidente da Célula de Walker (que inibe a formação de nuvens).

Fonte: Monitor Climático/Boletim de Monitoramento Climático. O Fenômeno El NiñoOscilação Sul: Teorias, Observações e Previsões. FUNCEME, Fortaleza.1997, v. 2, 31p.

\subsection{Sistemas Atmosféricos}

Os principais sistemas atmosféricos inibidores ou causadores de chuva sobre a região Nordeste do Brasil são descritos de forma resumida a seguir. Essa descrição é acompanhada com exemplos ilustrativos, onde são utilizadas imagens dos satélites da série METEOSAT, recepcionados diretamente pela estação de recepção de dados de satélite da FUNCEME, localizada na cidade de Fortaleza, estado do Ceará.

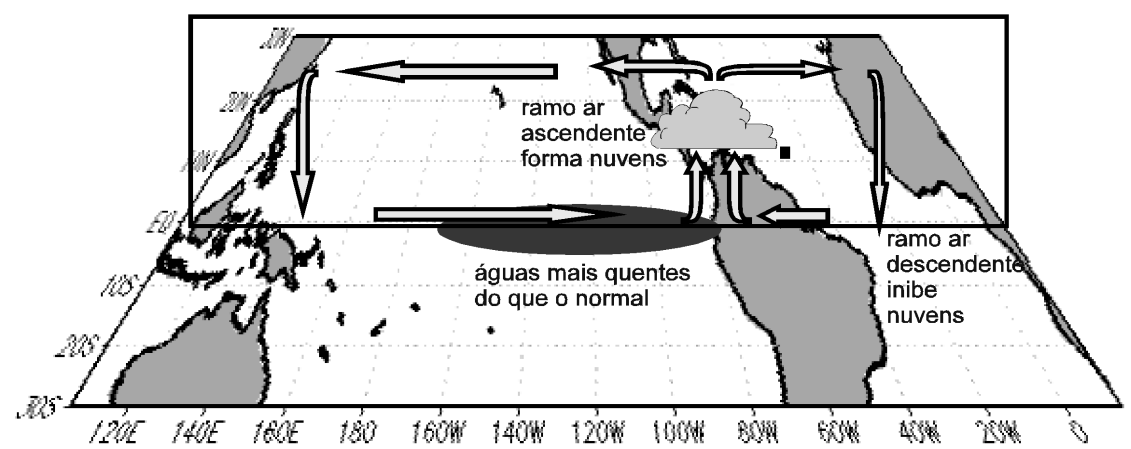

Figura 2. Esquematização da circulação atmosférica de grande escala no sentido zonal (Célula de Walker) modificada em associação ao episódio El Niño sobre o Oceano Pacífico. Sobre a região do Pacífico centro-leste, incluindo Peru/Equador, observa-se a ramo ascendente (favorável à formação de nuvens) da Célula de Walker e, por outro lado, sobre o Pacífico oeste/norte da Austrália e também no Atlântico Equatorial, incluindo o leste da Amazônia e norte do Semi-Árido Nordestino tem-se, consequentemente, o ramo descendente (que inibe a formação de nuvens).

Fonte: Monitor Climático/Boletim de Monitoramento Climático. O Fenômeno El NiñoOscilação Sul: Teorias, Observações e Previsões. FUNCEME, Fortaleza, 1997, v. 2, 31p. 


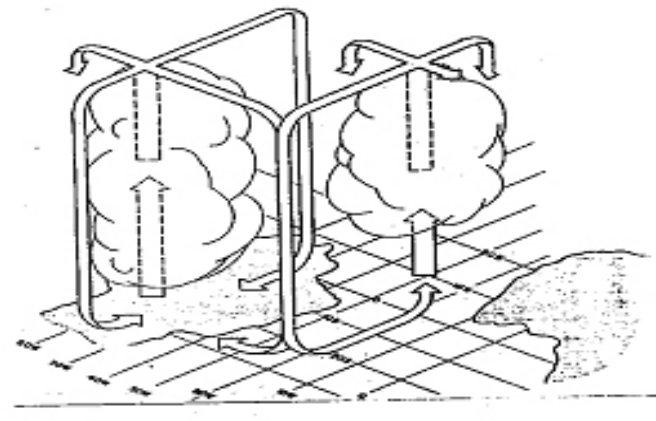

(a)

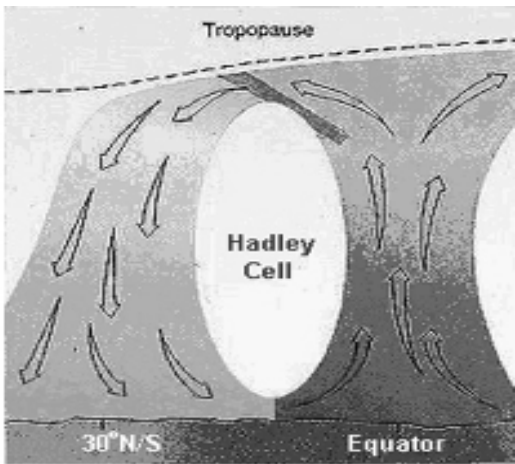

(b)

Figura 3. (a) Diagrama Esquemático da Circulação de Hadley-Walker sobre a América do Sul tropical e o setor do Atlântico Sul Tropical. A nebulosidade sobre o oceano representa a atividade convectiva sobre a Zona de Convergência Intertropical-ZCIT, e (b) diagrama esquemático da Célula de Hadley.

Fonte: (a) Climanálise/Boletim de Monitoramento e Análise Climática, Número Especial, 1986. INPE. São José dos Campos, SP. 125 págs. e

(b) http://ag.arizona.edu/ /milich/dry.html.

\subsubsection{Zona de Convergência Intertropical}

A Zona de Convergência Intertropical (ZCIT) pode ser definida como uma banda de nuvens que circunda a faixa equatorial do globo terrestre (Figuras 4 e 5), formada principalmente pela confluência dos ventos alísios do hemisfério norte com os ventos alísios do hemisfério sul, em baixos níveis (o choque entre eles faz com que o ar quente e úmido ascenda e provoque a formação das nuvens), baixas pressões, altas temperaturas da superfície do mar, intensa atividade convectiva e precipitação.

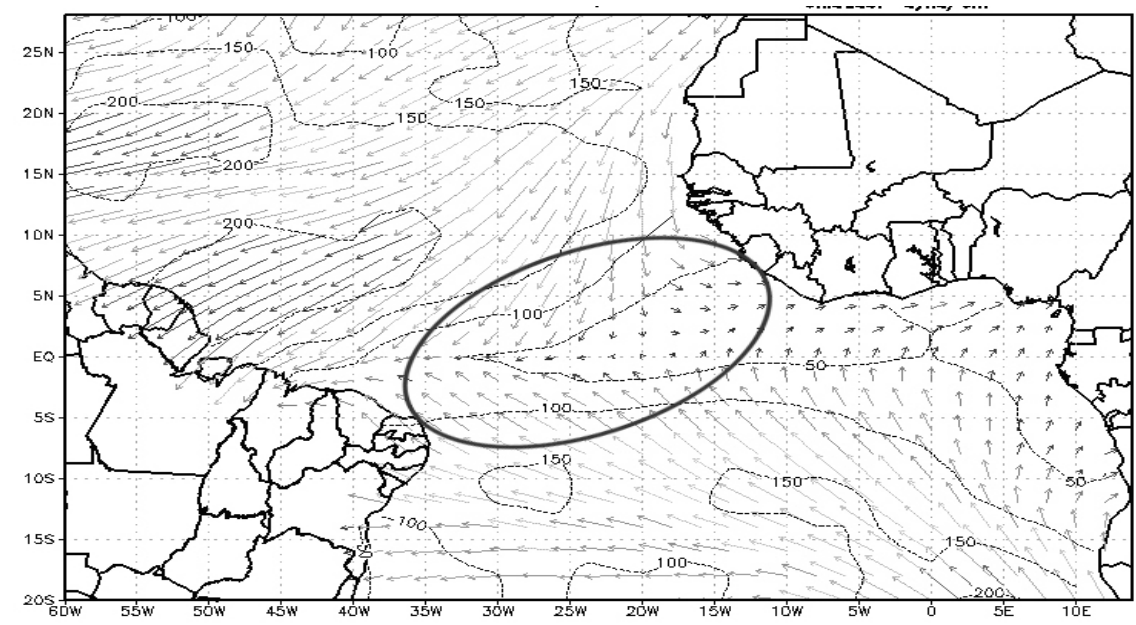

Figura 4. Eixo de confluência (circundado em vermelho) dos ventos alísios de sudeste com os de nordeste - ZCIT.

Fonte: Apostila do Curso de Meteorologia da FUNCEME, 1998. 


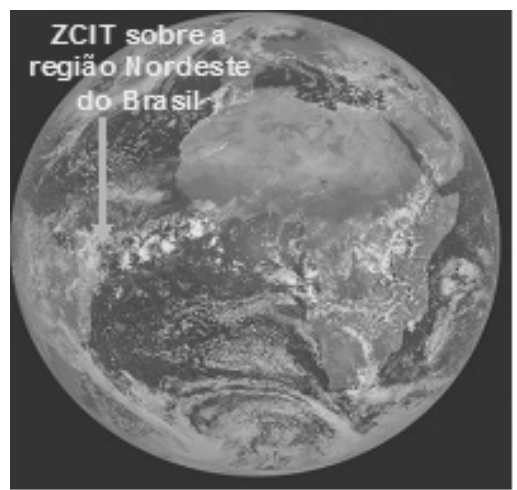

(a)

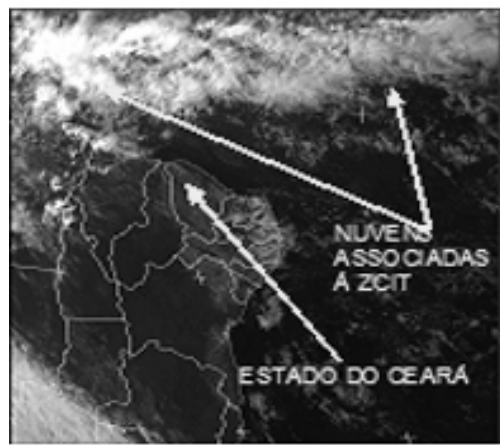

(c)

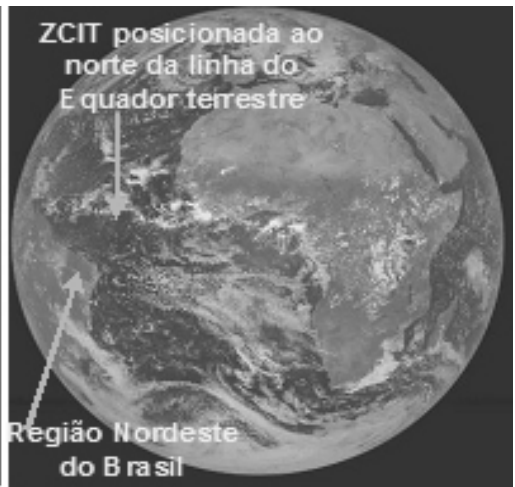

(b)

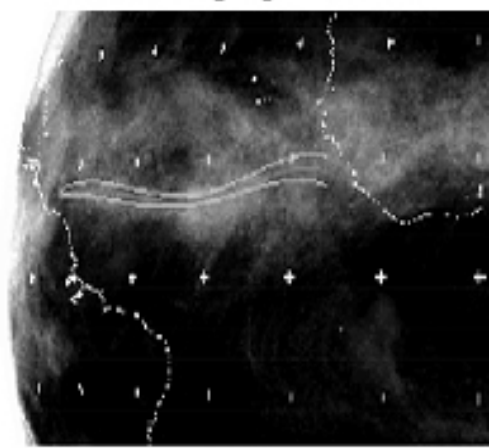

(d)

Figura 5. Zona de Convergência Intertropical-ZCIT mostrada através das imagens do satélite METEOSAT-7, recepcionadas pela estação de recepção de dados de satélite da FUNCEME. Figuras 5(a) e 5(c) (canal visível 21/03/2003 - 12:00 GMT) mostram a posição da ZCIT no mês de abril de 2003, período chuvoso da região Nordeste do Brasil, na qual o Ceará está inserido e Figuras 5(b) (canal visível - 08/10/2003 - 12:00 GMT) e 5(d) (canal infravermelho - composite de imagens) mostram a ZCIT no mês de outubro de 2003, fora do período chuvoso da região.

A ZCIT é o fator mais importante na determinação de quão abundante ou deficiente serão as chuvas no setor norte do Nordeste do Brasil. Normalmente ela migra sazonalmente de sua posição mais ao norte, aproximadamente $14^{\circ} \mathrm{N}$ em agosto-outubro para posições mais ao sul, aproximadamente 2 a $4^{\circ} \mathrm{S}$ entre fevereiro a abril. Esse deslocamento da ZCIT está relacionado aos padrões da Temperatura da Superfície do Mar (TSM) sobre essa bacia do oceano Atlântico Tropical, conforme já demonstrado em vários estudos(p. ex. Uvo, 1989).

A ZCIT é mais significativa sobre os oceanos, e por isso, a Temperatura da Superfície do Mar (TSM) é um dos fatores determinantes na sua posição e intensidade.

\subsubsection{Frente Fria}

Um outro importante mecanismo causador de chuvas no Nordeste do Brasil está ligado à penetração de frentes frias até às latitudes tropicais entre os meses de novembro e janeiro. 
As frentes frias são bandas de nuvens organizadas que se formam na região de confluência entre uma massa de ar frio (mais densa) com uma massa de ar quente (menos densa). A massa de ar frio penetra por baixo da quente, como uma cunha, e faz com que o ar quente e úmido suba, forme as nuvens e, conseqüentemente, as chuvas (Figuras 6 e 7).

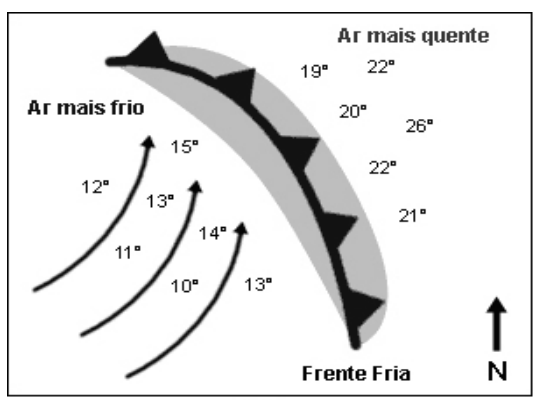

(a)

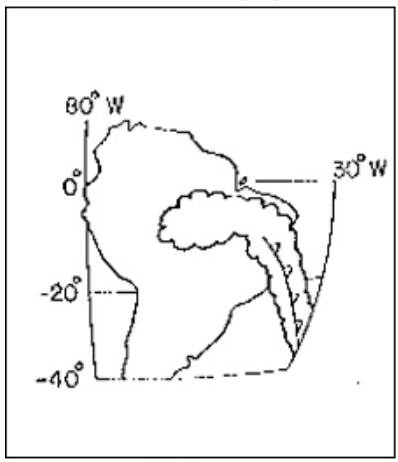

(c)

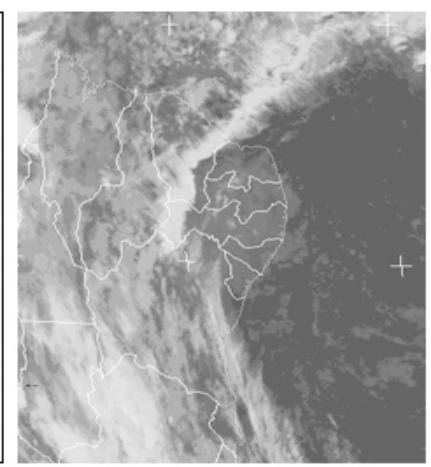

(d)

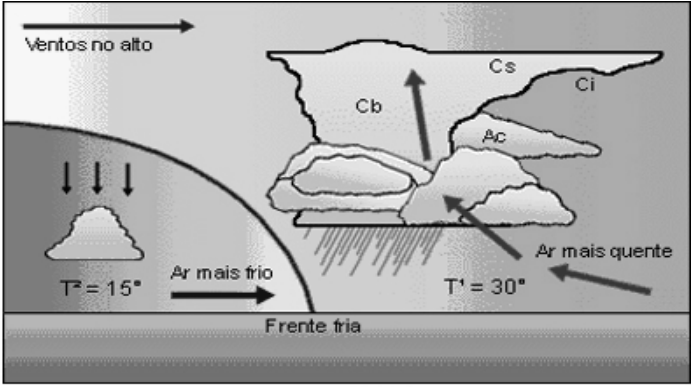

(b)

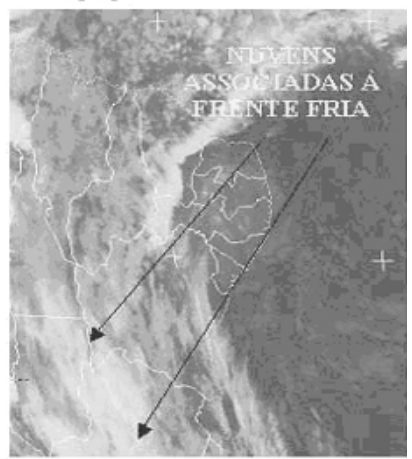

(e)

Figura 6. (a) e (b) - O tempo na superfície associada com uma frente fria. (Precipitação representada em áreas verdes), e (c) diagrama esquemático indicando a posição mais ao norte das frentes frias que influenciam as chuvas no Nordeste do Brasil, (d) a nebulosidade associada a elas estendendo-se até oeste da região Amazônica, e e) Imagem do satélite METEOSAT-7, recepcionada pela estação de recepção de dados de satélite da FUNCEME, mostrando o posicionamento de uma Frente Fria próxima ao sul do estado da Bahia.

Fonte das Figuras (a) e (b): http://www.brasgreco.com/weather/frentes/f_frias. $h t m /$.

\subsubsection{Vórtice Ciclônico de Altos Níveis}

Os Vórtices Ciclônicos de Altos Níveis (VCAN) que penetram na região Nordeste do Brasil formam-se no oceano Atlântico, principalmente entre os meses de novembro e março, e sua trajetória normalmente é de leste para oeste, com maior freqüência entre os meses de janeiro e fevereiro, conforme demonstrado por Gan e Kousky (1982). O tempo de vida desses sistemas varia em média, entre 7 a 10 dias.

Os VCANs são um conjunto de nuvens que, observado pelas imagens de satélite, têm a forma aproximada de um círculo girando no sentido horário. Na sua periferia há formação de nuvens causadoras de chuva e no centro há movimentos de ar de cima para baixo (subsidência), aumentando a pressão e inibindo a formação de nuvens (Figuras 7 e 8). 


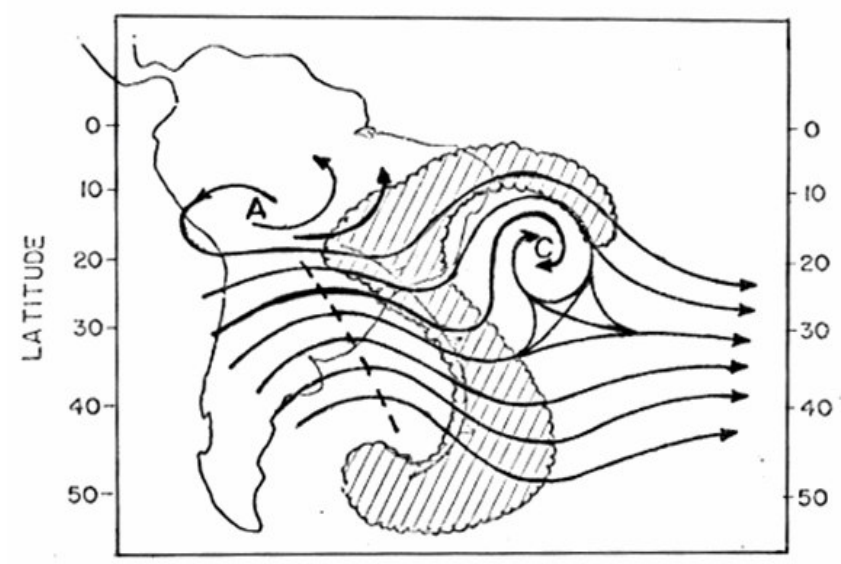

Figura 7. Diagrama esquemático da nebulosidade associada aos Vórtices Ciclônicos de Altos Níveis-VCAN.
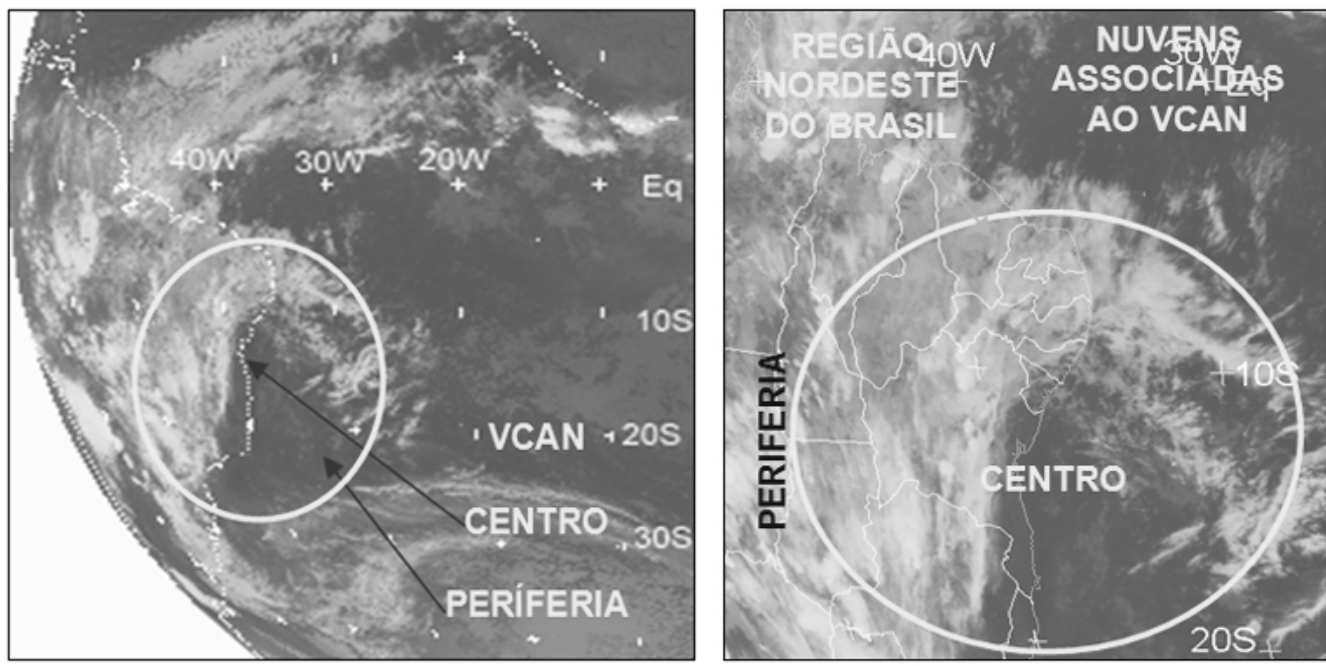

Figura 8. Imagens do satélite METEOSAT 7, canal infravermelho, recepcionada pela estação de recepção de dados de satélite da FUNCEME.

\subsubsection{Linhas de Instabilidade}

As Linhas de Instabilidade são bandas de nuvens causadoras de chuva, normalmente do tipo cumulus, organizadas em forma de linha (Figura 9), daí o seu nome. Sua formação se dá basicamente pelo fato de que com a grande quantidade de radiação solar incidente sobre a região tropical ocorre o desenvolvimento das nuvens cumulus, que atingem um número maior à tarde e início da noite, quando a convecção é máxima, com conseqüentes chuvas. Outro fator que contribui para o incremento das LI, principalmente nos meses de fevereiro e março, é a proximidade da ZCIT. Mais detalhes podem ser obtidos em Cavalcanti, 1982. 


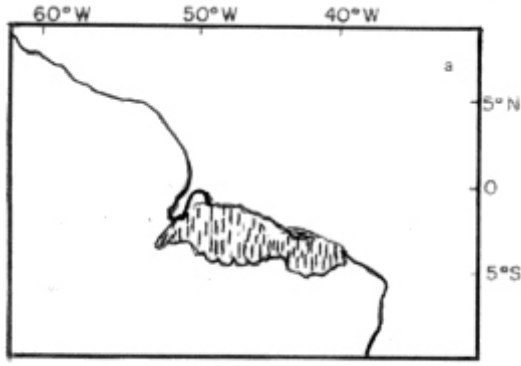

(a)

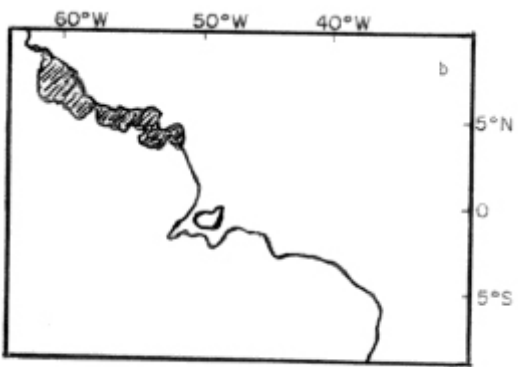

(b)

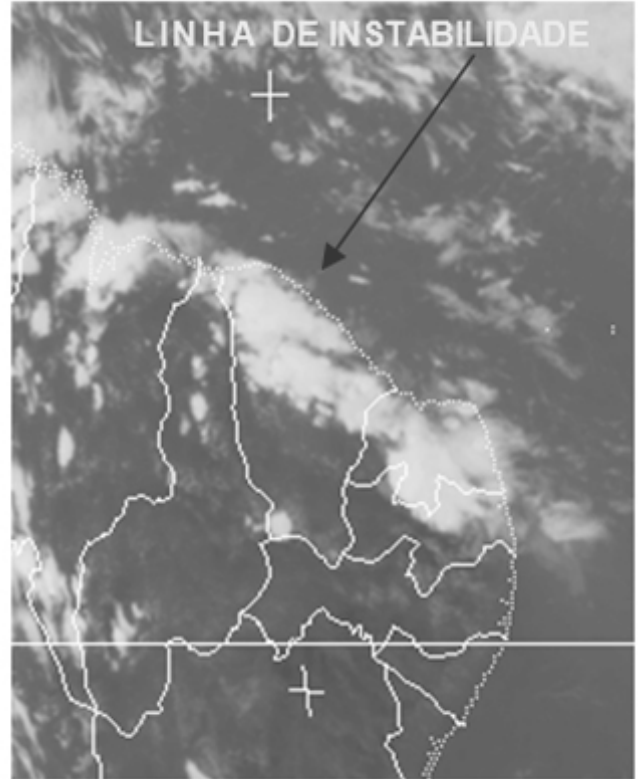

(c)

Figura 9. Diagrama esquemático da nebulosidade associada às Linhas de Instabilidade: a) fevereiro a maio, b) agosto a novembro, e c) Imagem do satélite METEOSAT-7, recepcionada pela estação de recepção de dados de satélite da FUNCEME, mostrando uma Linha de Instabilidade desde o litoral do estado do Maranhão até o estado do Rio Grande do Norte.

Fonte das Figuras (a) e (b): Cavalcanti, 1982.

\subsubsection{Complexos Convectivos de Mesoescala}

Os Complexos Convectivos de Mesoescala (CCMs) são aglomerados de nuvens que se formam devido às condições locais favoráveis como temperatura, relevo, pressão, etc., e provocam chuvas fortes e de curta duração, normalmente acompanhadas de fortes rajadas de vento. Os CCMs, na região subtropical, ocorrem preferencialmente durante os meses de primavera e de verão no hemisfério sul, formando-se no período noturno com um ciclo de vida entre 10 e 20 horas (vide Souza et al., 1998).

Normalmente as chuvas associadas a este fenômeno meteorológico ocorrem de forma isolada (Figuras 10). Um exemplo típico é relatado em Souza et al. (1998), onde ocorreram chuvas sobre a cidade de Fortaleza, no dia 24/04/97, durante 13 horas seguidas (entre 01:00h e 13:00h local). Ao final desse período havia chovido $270 \mathrm{~mm}$, correspondendo a $79 \%$ da climatologia do mês de abril, para o posto pluviométrico da Fundação Cearense de Meteorologia e Recursos Hídricos - FUNCEME (latitude $3^{\circ} 75^{\prime} \mathrm{S}$ - longitude $\left.38^{\circ} 53^{\prime} \mathrm{W}\right)$.

\subsubsection{Ondas de Leste}

As ondas de leste são ondas que se formam no campo de pressão atmosférica, na faixa tropical do globo terrestre, na área de influência dos 
ventos alísios, e se deslocam de oeste para leste, ou seja, desde a costa da África até o litoral leste do Brasil (Figura 11). Ele provoca chuvas principalmente na Zona da Mata que se estende desde o Recôncavo Baiano até o litoral do Rio Grande do Norte, mas, quando as condições oceânicas e atmosféricas estão favoráveis, as Ondas de Leste também provocam chuvas no estado do Ceará nos meses de junho, julho e agosto, principalmente na parte centro-norte do estado.

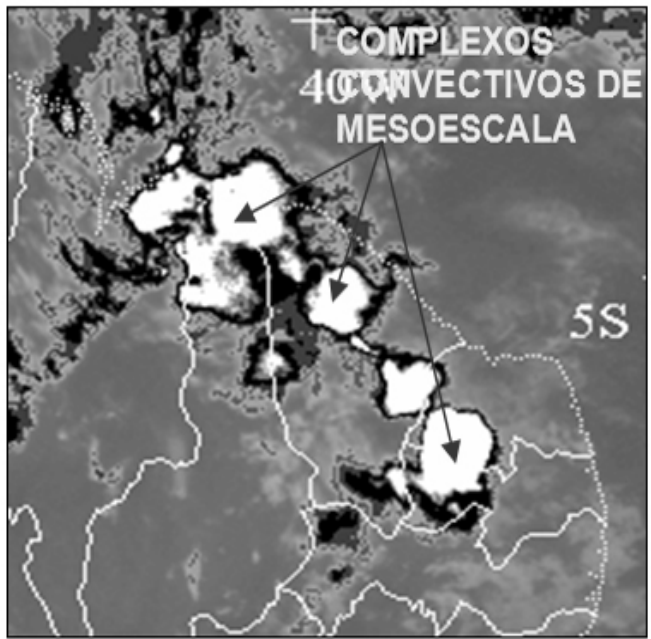

(a)

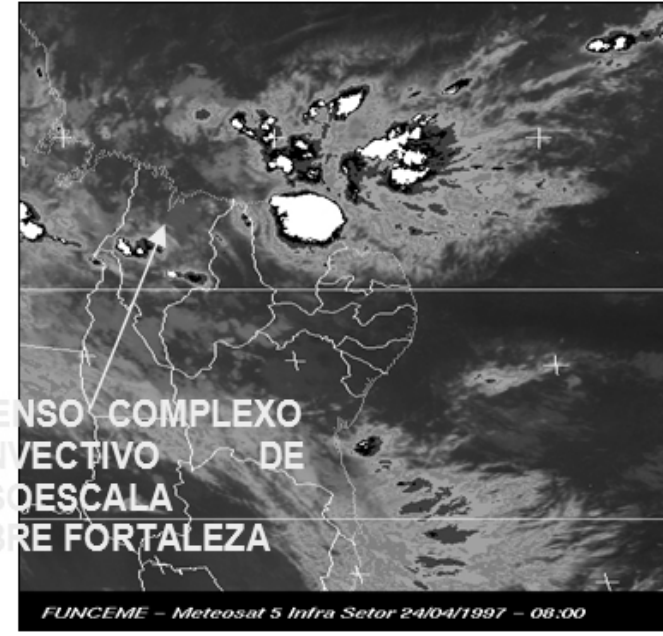

(b)

Figura 10. Imagens do Satélite Meteosat-7- canal infravermelho: a) dia 21/01/96 às 21:00h local, e b) dia 24/04/97 às 08:00h local, recepcionadas pela estação de recepção de dados de satélite da FUNCEME.

\subsubsection{Brisa Marítima e Brisa Terrestre}

As brisas marítimas e terrestres resultam do aquecimento e resfriamento diferenciais que se estabelecem entre a terra e a água (Fedorova, 2001). Durante o dia o continente se aquece mais rapidamente que o oceano adjacente, fazendo com que a pressão sobre o continente seja mais baixa que sobre o oceano. Isto faz com que o vento à superfície sopre do oceano para o continente, vento esse denominado de brisa marítima. A brisa marítima chega a penetrar até $100 \mathrm{~km}$ para dentro do continente. No período da noite o continente perde calor mais rapidamente que o oceano, fazendo com que esse fique com temperaturas mais elevadas se comparadas às do continente. Dessa forma a pressão fica maior sobre o continente, fazendo com que o vento sopre do litoral para o oceano, vento esse chamado de brisa terrestre. A brisa terrestre também afeta até $100 \mathrm{~km}$ para dentro do mar.

As brisas terrestre e marítima (Figura 12) nem sempre são percebidas. No nordeste do Brasil, por exemplo, onde os ventos alísios são persistentes e intensos durante todo o ano, quase sempre as brisas apenas contribuem para mudar um pouco a direção e a velocidade dessas. Dependendo da orientação da costa, a velocidade do vento, resultante da superposição alísio-brisa, pode ser maior ou menor que a do alísio (Varejão-Silva, 2001). 


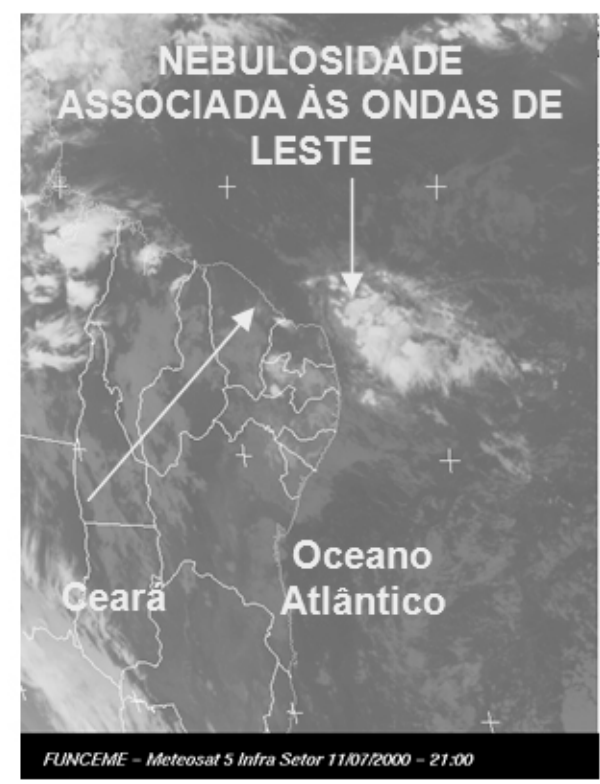

Figura 11. Imagem do Satélite Meteosat-7, canal infravermelho do dia 11/01/2000 às 21:00h local, recepcionada pela estação de recepção de dados de satélite da FUNCEME, mostrando nebulosidade que está se deslocando desde a costa da África até o litoral leste do Brasil.

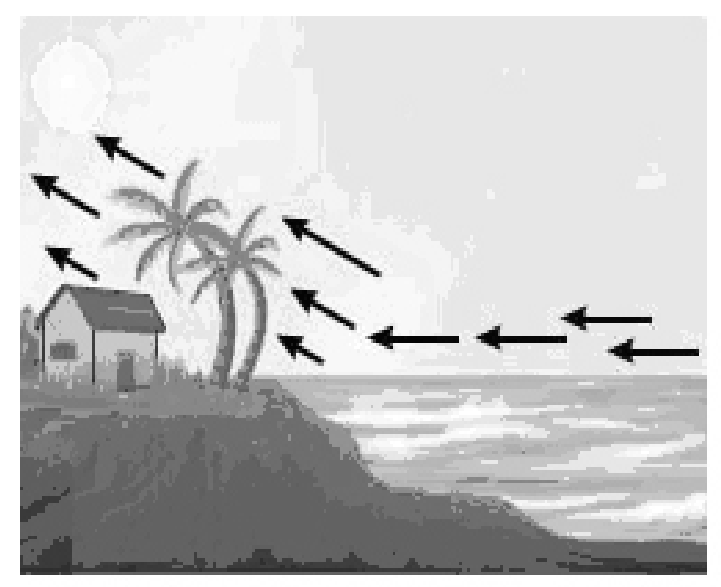

(a)

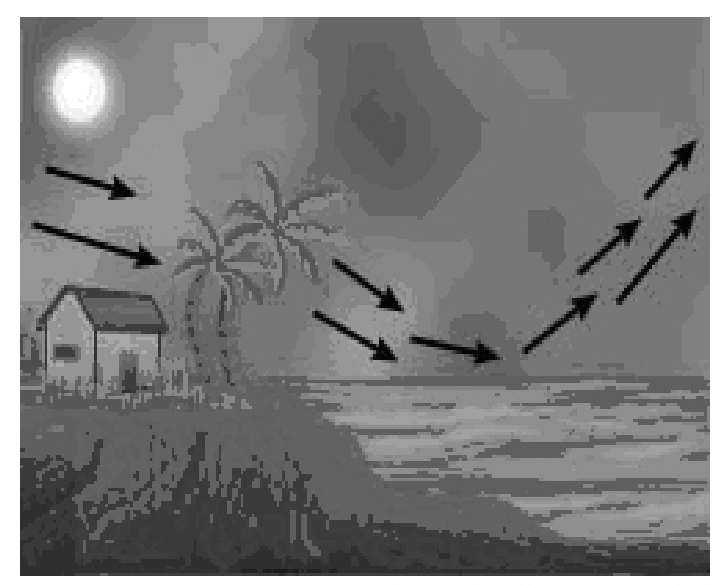

(b)

Figura 12. (a) Brisa Marítima e (b) Brisa Terrestre

Fonte: http://geocities.yahoo.com.br/saladefisica5/leituras/brisa.htm.

\subsection{Influência dos oceanos Pacífico e Atlântico no clima da região}

Em anos de El Niño, quando as águas superficiais da Bacia do Pacífico, em torno do Equador, e sobre o lado centro-leste, estão mais aquecidas, toda a convecção equatorial também se desloca para o leste, 
alterando assim o posicionamento da Célula de Walker. Devido à continuidade da circulação atmosférica, o ar quente sobre aquela região é empurrado, originando uma célula descendente sobre o Oceano Atlântico, próximo à região Nordeste do Brasil (NEB) e à Amazônia oriental. Dependendo da intensidade dessa célula de circulação e de sua fase de ocorrência, pode haver inibição da formação de nuvens e descida da Zona de Convergência Intertropical (ZCIT) e, conseqüentemente, pode haver deficiência das chuvas na região do NEB (extraído de Boletim de Monitoramento Climático Monitor Climático - Edição Especial Num. 02/1997 O fenômeno El Niño-Oscilação Sul: teorias, observações e previsões). Assim, o fenômeno El Niño, é um dos responsáveis pela redução das chuvas na região norte do Nordeste do Brasil (NEB).

Por outro lado, muitos trabalhos mostram a influência do Oceano Atlântico Tropical na distribuição das chuvas nas regiões tropicais do continente Sul-Americano, principalmente sobre o setor norte do Nordeste do Brasil (Hastenrath e Heller (1977); Moura e Shukla (1996); Uvo et al. (1994)).

O fenômeno El Niño (aquecimento acima do normal das águas do oceano Pacífico Equatorial), por exemplo, dependendo da intensidade e período do ano em que ocorre, é um dos responsáveis por anos considerados secos ou muito secos, principalmente quando acontece conjuntamente com o dipolo positivo do Atlântico (Dipolo do Atlântico: diferença entre a anomalia da Temperatura da Superfície do Mar-TSM na Bacia do Oceano Atlântico Norte e Oceano Atlântico Sul), que é desfavorável às chuvas. O fenômeno La Niña (resfriamento anômalo das águas do oceano Pacífico) associado ao dipolo negativo do Atlântico (favorável às chuvas), é normalmente responsável por anos considerados normais, chuvosos ou muito chuvosos na região.

A área hachurada na Figura 13 (a) indica a posição da ZCIT e o "AAN" Sistema de Alta Pressão do Atlântico Norte. As setas indicam a intensificação dos ventos alísios de nordeste. Quando as águas do Atlântico Norte estão mais frias que o normal, o Sistema de Alta Pressão do Atlântico Norte e os ventos alísios de nordeste intensificam-se. Se neste mesmo período o Atlântico Sul estiver mais quente que o normal, o Sistema de Alta Pressão do Atlântico Sul e os ventos alísios de sudeste enfraquecem. Este padrão favorece o deslocamento da ZCIT para posições mais ao sul da linha do Equador, e é propício à ocorrência de anos normais, chuvosos ou muito chuvosos para o setor norte do Nordeste do Brasil.

Na Figura 13 (b) a área hachurada indica a posição da ZCIT e o "AAS" Sistema de Alta Pressão do Atlântico Sul. As setas indicam a intensificação dos ventos alísios de sudeste. Quando as águas do Atlântico Sul estão mais frias que o normal, o Sistema de Alta Pressão do Atlântico Sul e os ventos alísios de sudeste intensificam-se. Se neste mesmo período as águas no Atlântico Norte estiverem mais quentes que o normal, o Sistema de Alta Pressão do Atlântico Norte e os ventos alísios de nordeste enfraquecem. Este padrão favorece o deslocamento da ZCIT para posições mais ao norte da linha do Equador e é propício à ocorrência de anos secos ou muitos secos para o setor norte do Nordeste do Brasil.

Em função disso, o monitoramento dos padrões oceânicos e atmosféricos durante a estação das chuvas é de fundamental importância para 
que as previsões de tempo e de clima possam ser geradas com maior grau de confiabilidade possível.

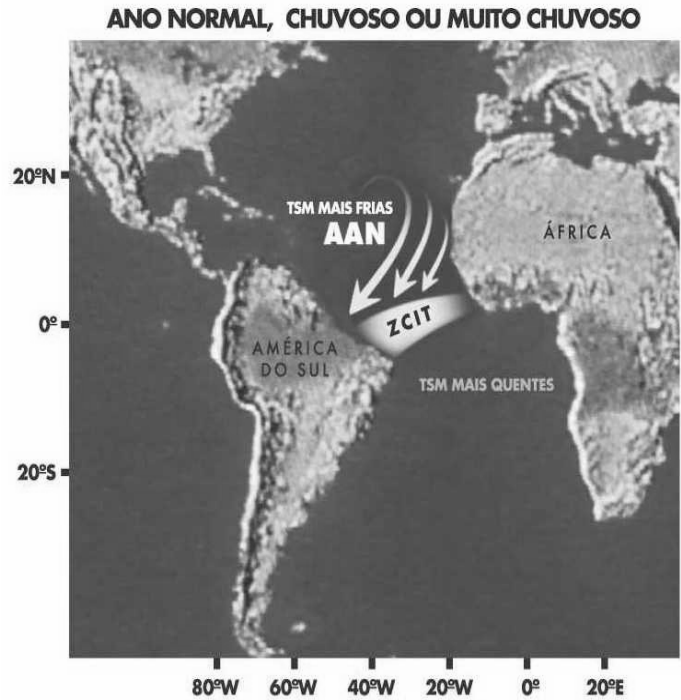

(a)

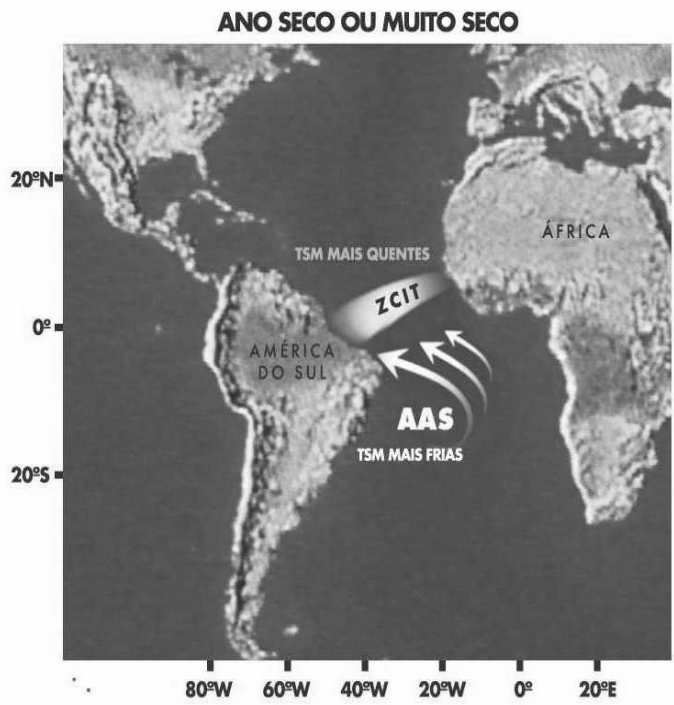

(b)

Figura 13. Esquema mostrando, de maneira simplificada, os padrões oceânicos e atmosféricos que contribuem para a ocorrência de anos muito secos, secos, normais, chuvosos e muito chuvosos, na parte norte da região Nordeste do Brasil.

\section{Considerações Finais}

Muitos trabalhos (Alves et al., 1997, por exemplo) mostram a influência do Oceano Atlântico Tropical na distribuição das chuvas nas regiões tropicais do continente Sul-Americano, principalmente sobre o setor norte do Nordeste do Brasil. Estes trabalhos mostram que, o El Niño, quando acontece conjuntamente com o dipolo positivo do Atlântico (Dipolo do Atlântico: diferença entre a anomalia da Temperatura da Superfície do Mar-TSM na Bacia do Oceano Atlântico Norte e Oceano Atlântico Sul), que é desfavorável às chuvas, causam anos secos ou muito secos no NEB. O fenômeno La Niña (resfriamento anômalo das águas do oceano Pacífico) associado ao dipolo negativo do Atlântico (favorável às chuvas), é normalmente responsável por anos considerados normais, chuvosos ou muito chuvosos na região. Por fim, quando as águas do Pacífico estão em condições normais e o dipolo do Atlântico negativo (positivo), a probabilidade de se ter um ano normal ou chuvoso (seco) também é alta.

Na Tabela 1 , apresenta-se, para o período compreendido entre 1995 e 2003, a classificação do período chuvoso para o estado do Ceará, em função dos padrões de TSM observados no Pacífico e Atlântico. Verifica-se através das informações contidas na Tabela 1 que o modelo conceitual apresentado anteriormente apresenta boa concordância com os dados observados. 
Tabela 1. Intensidade dos Fenômenos El Niño/La Niña; classificação do Dipolo do Atlântico, e os impactos nas chuvas do estado do Ceará (período de janeiro a maio), para o período de 1995 a 2003, em função dos padrões de TSM observados no Pacífico e Atlântico, nesses anos (A média histórica anual de chuva para o estado do Ceará é de aproximadamente $850 \mathrm{~mm}$.).

\begin{tabular}{|c|c|c|c|c|}
\hline Ano & El Niño & La Niña & $\begin{array}{l}\text { Dipolo do } \\
\text { Atlântico }\end{array}$ & $\begin{array}{c}\text { Classificação } \\
\text { Climática } \\
\text { (O ano foi considerado) }\end{array}$ \\
\hline 1995 & Moderado & - & $\begin{array}{l}\text { Favorável } \\
\text { (Negativo) }\end{array}$ & Chuvoso \\
\hline 1996 & - & Fraca & $\begin{array}{l}\text { Desfavorável } \\
\text { (Positivo) }\end{array}$ & Normal a Chuvoso \\
\hline 1997 & Neutro & Neutra & $\begin{array}{l}\text { Desfavorável' } \\
\text { (Positivo) }\end{array}$ & Seco \\
\hline 1998 & Forte & - & $\begin{array}{l}\text { Desfavorável } \\
\text { (Positivo) }\end{array}$ & Muito Seco \\
\hline 1999 & - & Forte & $\begin{array}{l}\text { Favorável } \\
\text { (Negativo) }\end{array}$ & Normal \\
\hline 2000 & - & Moderada & $\begin{array}{l}\text { Favorável } \\
\text { (Negativo) }\end{array}$ & Normal \\
\hline 2001 & - & Moderada & Neutro & Normal a Seco \\
\hline 2002 & Fraco & - & $\begin{array}{l}\text { "Favorável } \\
\text { (Negativo) }\end{array}$ & Normal \\
\hline 2003 & Neutro & Neutra & $\begin{array}{l}\text { Favorável } \\
\text { (Negativo) }\end{array}$ & Normal \\
\hline
\end{tabular}

Fonte dos dados: FUNCEME e INPE/CPTEC

\section{Referências Bibliográficas}

Alves, J.M.B., E.B. de Souza, C. A Repelli, M. I. Vitorino e Ferreira, N.S., 1997. Episódios de La Niña na Bacia do Oceano Pacífico Equatorial e a Distribuição de Chuvas no Setor Norte do Nordeste Brasileiro. Rev. Bras. de Meteor., v. 12, 63-76.

Azevedo, P.V., B.B. da Silva e M.F.G. Rodrigues, 1998. Previsão Estatística das Chuvas de Outono no Estado do Ceará. Rev. Bras. de Meteor., v. 13, no. 1, 19-30.

Boletim de Monitoramento Climático- Monitor Climático - Edição Especial, 1997. O Fenômeno El Niño- Oscilação Sul: Teorias, Observações e Previsões. FUNCEME, Fortaleza, CE. no. 2, 31 págs.

Boletim de Monitoramento e Análise Climática - Climanálise - Número Especial, 1986. INPE. São José dos Campos, SP. 125 págs.

Cavalcanti, I.F.A., 1982. Um estudo Sobre Interações Entre Sistemas de Circulação de Escala Sinótica e Circulações Locais. Dissertação de Mestrado em Meteorologia, Instituto Nacional de Pesquisas Espaciais, São José dos Campos, SP. 121 págs.

Fedorova, N, 2001. Meteorologia Sinótica. V2, 242 págs, Editora e gráfica UniversitáriaUFPel.

Gan, M.A e Kousky, V.E., 1982. Um Estudo Observacional sobre as Baixas Frias da Alta Troposfera nas Latitudes Subtropicais do Atlântico Sul e Leste do Brasil. INPE, São José dos Campos, SP. 25 págs.

Hastenrath, S., Heller, L., 1977. Dynamics of climate hazards in Northeast Brazil. Quart. J. Roy. Meteorological Society, v. 103, 77-92. 
Moura, A. D., Shukla, J., 1981. On the dynamics of droughts in the Northeast Brazil: Observations, theory and numerical experiments with a general circulation model., Journal of Atmospheric Sciences, v. 38, n.12, 2653 - 2675.

Souza, E.B., J.M.B. Alves e C.A Repelli, 1998. Um Complexo Convectivo de Mesoescala Associado à Precipitação Intensa sobre Fortaleza-CE. Rev. Bras. de Meteor., v. 13, n. 2, 01-14.

Uvo, C. R. B., Repelli, C. A., S. Zebiack and Kushinir, Y., 1994. A Study on the influence of the Pacific and Atlantic on the Northeast Brazil Monthly Precipitation Unsing Singular Value Decomposition (SVD). To be submited to Journal of Climate.

Uvo, C.R. B. e R. Berndtsson, 1996. Regionalization and Spatial Properties of Ceará State Rainfall in Northeast Brazil. J. Geoph. Res., vol. 101, no. D2, 4221-4233.

Uvo, C.R.B., 1989. A Zona de Convergência Intertropical (ZCIT) e sua Relação com a Precipitação da Região Norte do Nordeste Brasileiro. Dissertação de Mestrado em Meteorologia, Instituto Nacional de Pesquisas Espaciais, São José dos Campos, SP. 82 págs.

Varejão-Silva, M. A, 2001. Meteorologia e Climatologia. PAX Gráfica e Editora Ltda, 2a Edição, 532 págs. 